EXPERT REVIEW

\title{
Mechanisms of action of fluvoxamine for COVID-19: a historical review
}

\author{
Yaeko Hashimoto $^{1,2}$, Takuji Suzuki ${ }^{1}$ and Kenji Hashimoto ${ }^{2 \bowtie}$ \\ (c) The Author(s), under exclusive licence to Springer Nature Limited 2021
}

\begin{abstract}
The ongoing coronavirus disease 2019 (COVID-19) pandemic caused by the novel severe acute respiratory syndrome coronavirus 2 (SARS-CoV-2) accelerates the discovery of prophylactic and therapeutic drugs for persons infected with the virus. Drug repurposing for the COVID-19 pandemic has received particular attention. Increasing clinical data suggest that antidepressant use in early-stage subjects with COVID-19 might be associated with a reduced risk of intubation or death. Among the antidepressants, fluvoxamine is the most attractive drug for mild to moderate subjects with COVID-19. In this article, we review the mechanisms of action (i.e., serotonin transporter, sigma-1 receptor, and acid sphingomyelinase) of fluvoxamine for COVID-19. Furthermore, we discuss a possible link between maternal COVID-19 infection and a risk for neuropsychiatric disorders (i.e., autism spectrum disorder and schizophrenia) in offspring.
\end{abstract}

Molecular Psychiatry (2022) 27:1898-1907; https://doi.org/10.1038/s41380-021-01432-3

\section{INTRODUCTION}

The coronavirus disease 2019 (COVID-19) is an acute respiratory disease caused by the novel RNA virus severe acute respiratory syndrome coronavirus 2 (SARS-CoV-2). Since the first report of SARS-CoV-2-infected patients in Wuhan, China, in December 2019, the number of persons with COVID-19 has markedly increased worldwide. As we approach 2022, we are experiencing a big wave of COVID-19 caused by SARS-CoV-2 variants (i.e., delta, lambda, $\mathrm{mu}$, and omiclone). Approximately $80 \%$ of SARS-CoV-2-infected subjects is mild to moderate (stage I) (Fig. 1). The remaining 20\% may convert to severe clinical stages in about 1 week (stage II). Subsequently, a part of stage II ( 5\% of total) may convert to stage III, ultimately resulting in intubation or death (Fig. 1) [1]. Furthermore, SARS-CoV-2 infection seems to cause detrimental effects in the central nervous system (CNS), resulting in psychiatric and neurological symptoms [2-5]. A nationwide longitudinal study in China showed a long-term mental health impact in persons with COVID-19 [6].

With the current COVID-19 pandemic, drug repurposing is an important approach to discover promptly prophylactic or therapeutic drugs for persons with COVID-19 [7-10]. A number of candidates have been investigated in SARS-CoV-2-infected patients since early 2020 [11]. Studies using in vitro or in silico assays discovered a number of candidates from approved inexpensive drugs. However, most candidates have no beneficial effects in in vivo models [12] or SARS-CoV-2-infected patients [13]. According to clinical trial reports, some promising candidates, such as hydroxychloroquine, lopinavir-ritonavir, and ivermectin, were ineffective in the treatment of patients with COVID-19 [14-19].

Increasing clinical data suggest that the use of antidepressants, such as selective serotonin reuptake inhibitor (SSRI) and serotoninnorepinephrine reuptake inhibitor (SNRI), might be associated with a reduced risk of clinical deterioration in SARS-CoV-2-infected patients. In November 2020, Dr. Lenze et al. reported that the SSRI fluvoxamine could prevent clinical deterioration in early-stage COVID-19 outpatients [20]. Subsequently, Hoertel et al. reported that the use of antidepressants, such as SSRIs and SNRIs, may be associated with reduced risk of intubation or death in hospitalized SARS-CoV-2-infected patients [21]. At present, the old SSRI fluvoxamine may be new hope for the COVID-19 pandemic [22].

In this article, we review the mechanisms of action of fluvoxamine and other antidepressants for COVID-19 and discuss a possible link between maternal infection of SARS-CoV-2 and the risk for neuropsychiatric disorders in offspring, since the number of SARS-CoV-2-infected pregnant women has been increasing worldwide.

\section{THE USE OF ANTIDEPRESSANTS AND ANTIPSYCHOTICS IN COVID-19 PATIENTS \\ Fluvoxamine}

In November 2020, Dr. Lenze et al. reported that the SSRI fluvoxamine could prevent clinical deterioration in adult outpatients with COVID-19. In the study, clinical deterioration did not occur in the fluvoxamine group $(n=80)$, but occurred in six from the placebo group $(n=72)$ [20]. This study's sample size was small, hence, strongly encouraged further trials using a large sample size.

In February 2021, Seftel and Boulware [23] reported a prospective, non-randomized observational cohort study at the Golden Gate Fields horse racing track in Berkeley, California. Hospitalization incidence in the fluvoxamine-treated $(n=65)$ and observation-alone $(n=48)$ groups was 0 and 6 , respectively. Among the six patients of the observation-alone group, two were

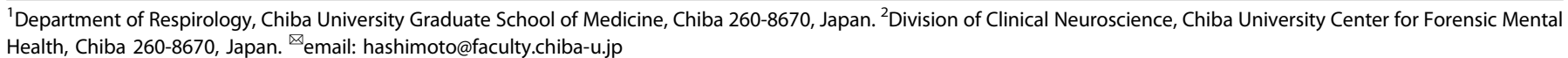




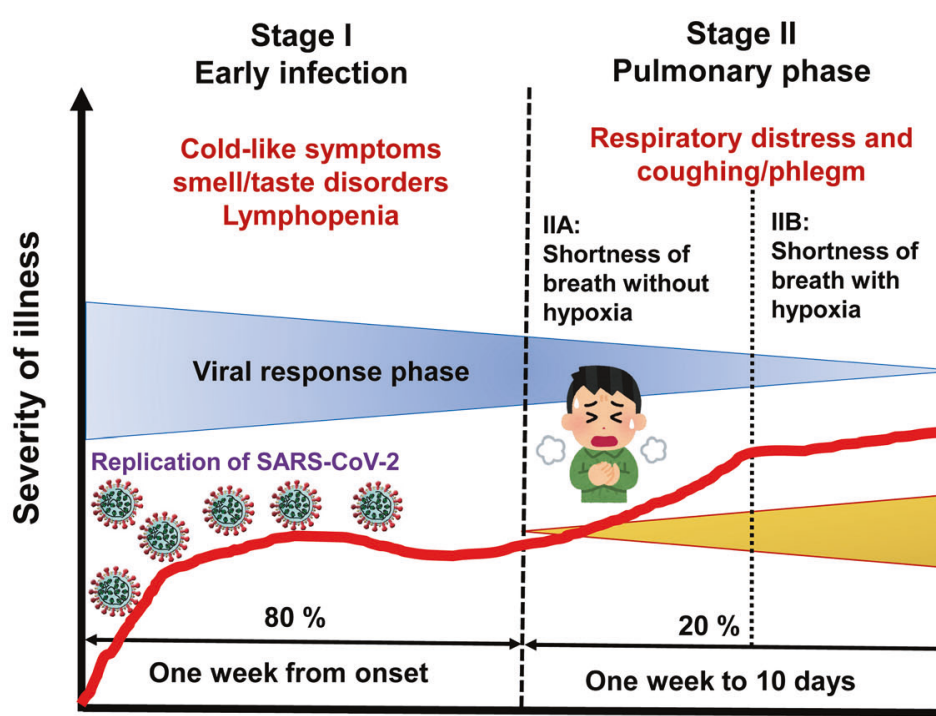

Onset
Stage III

\section{Hyperinflammation phase}

ARDS, SIRS/Shock, Cardiac Failure
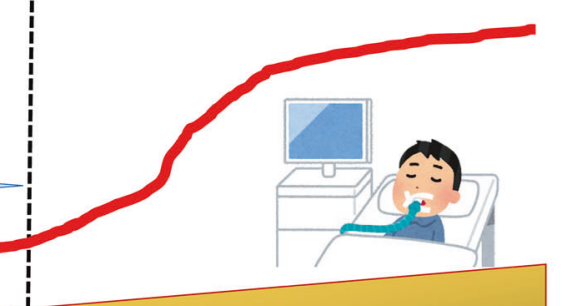

Host inflammatory response phase

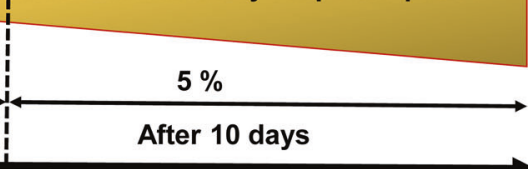

Time course

\section{Treatment Early intervention by fluvoxamine}

Fig. 1 The clinical course of COVID-19 and early intervention by fluvoxamine. The three escalating phases of COVID-19 progression, with associated symptoms. Approximately $80 \%$ of SARS-CoV-2-infected subjects is mild to moderate (stage I). The remaining $20 \%$ may convert to severe clinical stages in about 1 week (stage II). Subsequently, the part of stage II ( $5 \%$ of total) may convert to stage III, ultimately resulting in intubation or death. Being a cheap antidepressant, fluvoxamine can be used in the early-stage of COVID-19. However, its use for COVID-19 was not yet approved. ARDS acute respiratory distress syndrome, SIRS systemic inflammatory response syndrome. A slight modification with Fig. 1 in the reference [1]. Some materials of the figure have been designated using resources from www.irasutoya.com.

required to stay in the intensive care unit (ICU) with mechanical ventilation, of which one died [23]. On April 23, 2021, fluvoxamine was added to the US National Institutes of Health (NIH) COVID-19 Guidelines Panel, although evidence for fluvoxamine efficacy was insufficient.

In October 2021, Reis et al. [24] reported a placebo-controlled, randomized, adaptive, platform trial of fluvoxamine in unvaccinated and symptomatic SARS-CoV-2-infected Brazilian adult patients. Patients enrolled in this trial have a known risk factor for severe disease progression [24] and were randomly assigned to either fluvoxamine (100 mg twice daily for 10 days) or a placebo. The proportion of patients observed in an emergency room for $6 \mathrm{~h}$ or hospitalized was lower for the fluvoxamine group $(n=741)$ compared to the placebo group $(n=756)$ (relative risk $=0.68,95 \%$ Bayesian credible interval $=0.52-0.88$ ) [24]. There was one death in the fluvoxamine group and 12 in the placebo group. There were no significant differences in the number of treatmentemergent adverse events between the two groups [24]. This study with a large sample size shows that the treatment with fluvoxamine (100 mg twice daily for 10 days) among high-risk outpatients with early-diagnosed COVID-19 could reduce the need for extended emergency room observation or hospitalization. In this TOGETHER study, other candidates, such as hydroxychloroquine, lopinavir-ritonavir, metformin, and ivermectin, had no beneficial effects for patients with COVID-19 [16, 24, 25]. A recent open-label, prospective cohort study using ICU patients $(n=51)$ with COVID-19 showed that fluvoxamine (100 mg three times daily for 15 days) significantly [hazard ratio $(\mathrm{HR})=0.58,95 \% \mathrm{Cl}=$ $0.36-0.94, P=0.027]$ decreased the mortality compared to the matched control group [26].

In November 2021, Oskotsky et al. [27] reported the results of retrospective cohort study of COVID-19 patients treated with SSRIs using electronic health records of 87 health care centers across the US. This study included COVID-19 patients $(n=470)$ receiving fluoxetine only, COVID-19 patients $(n=481)$ receiving fluoxetine or fluvoxamine, and COVID-19 patients $(n=2898)$ receiving other SSRIs. Compared with matched untreated control COVID-19 patients, relative risk of mortality was reduced among patients treated with any SSRI (relative risk $=0.92,95 \% \mathrm{Cl}=0.85-0.99$, adjusted $P=0.03$ ), fluoxetine (relative risk $=0.72,95 \% \mathrm{Cl}=$ 0.54-0.97, adjusted $P=0.03$ ), and fluoxetine or fluvoxamine (relative risk $=0.74,95 \% \mathrm{Cl}=0.55-0.99$, adjusted $P=0.04$ ). In contrast, there was not significant (relative risk $=0.92,95 \% \mathrm{Cl}=$ 0.84-1.00, adjusted $P=0.06$ ) between SSRIs other than fluoxetine or fluvoxamine and risk of death. Among SSRIs, fluoxetine and fluvoxamine may be prophylactic SSRIs for COVID-19.

Collectively, fluvoxamine could likely be a prophylactic drug for early-stage SARS-CoV-2-infected patients [7, 22]. However, further multicenter randomized double-blind studies with a large sample size are needed.

\section{Other antidepressants}

An observational multicenter retrospective cohort study in France revealed a significant association between antidepressant use and reduced risk of intubation or death $(\mathrm{HR}=0.56,95 \% \mathrm{Cl}=0.43-0.73, P$ $<0.001$ ) in COVID-19 hospitalized patients [21]. There were significant associations between the use of SSRIs ( $H R=0.51,95 \%$ $\mathrm{Cl}=0.316-0.72, \quad P<0.001)$ and non-SSRIs $(\mathrm{HR}=0.65,95 \% \mathrm{Cl}=$ $0.45-0.93, P=0.018$ ). Among SSRIs used in this study, the authors showed the results of citalopram $(n=21, \mathrm{HR}=0.50,95 \% \mathrm{Cl}=$ 0.14-1.76, $P=0.283)$, escitalopram $(n=63, \mathrm{HR}=0.46,95 \% \mathrm{Cl}=$ 0.27-0.79, $\quad P=0.005)$, fluoxetine $(n=30, \quad \mathrm{HR}=0.26, \quad 95 \%$ $\mathrm{Cl}=0.09-0.75, P=0.013)$, paroxetine $(n=63, \mathrm{HR}=0.53,95 \% \mathrm{Cl}=$ $0.30-0.94, P=0.030)$, and sertraline $(n=22, \mathrm{HR}=0.75,95 \% \mathrm{Cl}=$ $0.29-1.95, P=0.554$ ). Only one subject treated with fluvoxamine was included in this study since it was unpopular in France. Interestingly, among the 577 patients admitted to the ICU, antidepressant use was significantly associated with reduced risk of intubation or death. In an Exploratory analysis, three SSRIs (escitalopram, fluoxetine, and paroxetine) were significantly associated with reduced risk of intubation or death [21].

Furthermore, in an observational study in Italy, hospitalized COVID-19 patients $(n=34)$ treated with antidepressants (i.e., sertraline, escitalopram, citalopram, paroxetine, venlafaxine, and 
Table 1. Affinity and pharmacology of the antidepressants and antipsychotics for sigma-1 receptor and action at ASM.

\begin{tabular}{llll}
\hline Antidepressants & Ki $(\mathbf{n M})$ for sigma-1 receptor & Action at sigma-1 receptor & Functional inhibitor at ASM \\
\hline Fluvoxamine (SSRI) & $36^{\mathrm{a}}$ or $17.0^{\mathrm{b}}$ & Agonist & Yes \\
\hline Sertraline (SSRI) & $57^{\mathrm{a}}$ or $31.6^{\mathrm{b}}$ & Antagonist & Yes \\
\hline Fluoxetine (SSRI) & $240^{\mathrm{a}}$ or $191.2^{\mathrm{b}}$ & Agonist & Yes \\
\hline Escitalopram (SSRI) & $288.3^{\mathrm{b}}$ & Agonist & Yes \\
\hline Citalopram (SSRI) & $292^{\mathrm{a}}$ or $403.8^{\mathrm{b}}$ & Agonist & Yes \\
\hline Imipramine (TCA) & $343^{\mathrm{a}}$ & Agonist & Yes \\
\hline Desipramine (TCA) & $1,987^{\mathrm{a}}$ & & Yes \\
\hline Paroxetine (SSRI) & $1,893^{\mathrm{a}}$ or $2,041^{\mathrm{b}}$ & & Yes \\
\hline Duoxetine (SNRI) & $3,533^{\mathrm{b}}$ & & Yes \\
\hline Venlafaxine (SNRI) & $>10,000^{\mathrm{b}}$ & & Yes \\
\hline Milnacipran (SNRI) & $>10,000^{\mathrm{b}}$ & & \\
\hline Mirtazapine (NaSSA) & $>10,000^{\mathrm{b}}$ & & Yes \\
\hline Antipsychotics & $\mathrm{Ki}(\mathrm{nM})$ & Action & Functional inhibitor of ASM \\
\hline Haloperidol & $4^{\mathrm{c}}$ & Antagonist & No \\
\hline Chlorpromazine & $180^{\mathrm{c}}$ & Antagonist & Yes
\end{tabular}

A slight modification of the table of [7] and [92].

SSRI selective serotonin reuptake inhibitor, SNRI serotonin noradrenaline reuptake inhibitor, TCA tricyclic antidepressant, NaSSA noradrenergic and specific serotonergic antidepressant.

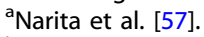

bishima et al. [63].

'Tam et al. [33].

duloxetine) before admission until discharge from the hospital had a lower incidence of severe acute respiratory distress syndrome (ARDS) than those $(n=368)$ treated without antidepressant [28]. Interestingly, blood levels of interleukin-6 (IL-6) from recovered patients of the antidepressant-treated group were significantly lower than those of recovered patients of not-treated group [28]. It suggests that modulation of IL- 6 production by antidepressant may play a role in the beneficial effects of the antidepressant-treated group. These data strongly encourage future randomized, double-blind trials using these SSRIs (or SNRIs) for COVID-19.

In a recent systematic review and meta-analysis, any mental disorder (i.e., psychotic, mood, and anxiety disorders) present in COVID-19 patients was associated with an increased risk of mortality (odds ratios $=2.00,95 \% \mathrm{Cl}=1.58-2.54$ ). Mortality was associated with the use of antipsychotics (odds ratios $=3.71,95 \% \mathrm{Cl}=$ 1.74-7.91), anxiolytics (odds ratios $=2.58,95 \% \mathrm{Cl}=1.22-5.44$ ), and antidepressants (odds ratios $=2.23,95 \% \mathrm{Cl}=1.06-4.71$ ) [29]. In contrast to antipsychotics and anxiolytics, mortality risk associated with antidepressants was not increased after the adjustment for age, sex, and other covariables. This study shows that antidepressant exposure was not associated with COVID-19 mortality, whereas antipsychotic and anxiolytic exposure was associated with COVID-19 mortality [29].

El-Battrawy et al. [30] reported a systematic analysis of concomitant arterial hypertension in COVID-19 patients. The mortality rate $(29.6 \%)$ of patients with concomitant hypertension $(n=2850)$ was significantly higher than that $(11.3 \%)$ of patients without arterial hypertension $(n=2960)$, suggesting a risk factor for mortality. By contrast, antidepressant use at admission $(n=$ 746) might be a positive independent predictor of mortality ( $\mathrm{HR}=$ 2.94, 95\% Cl=1.60-5.43, $P=0.001$ ) [30], inconsistent with the previous reports $[21,29]$. The detailed information (i.e., SSRI or SNRI) of the antidepressants used in this article was not disclosed.

Collectively, antidepressant use might seem to be associated with reduced risk for a severe clinical course in COVID-19 patients. Further randomized, double-blind study using a large sample size is needed to identify specific antidepressants for COVID-19.
Typical antipsychotic drugs: haloperidol and chlorpromazine A multicenter observational study in France showed that haloperidol use $(n=39)$ was not associated $(\mathrm{HR}=1.30,95 \% \mathrm{Cl}$ $=0.74-2.28, P=0.335$ ) with the risk of intubation or death in hospitalized COVID-19 adult patients $(n=15,121)$ [31]. Furthermore, Hoertel et al. [32] reported an observational study of chlorpromazine among COVID-19 hospitalized patients of $(n=$ $14,340)$ [32]. The primary analysis showed no significant association ( $\mathrm{HR}=2.01,95 \% \mathrm{Cl}=0.75-5.40, P=0.163)$ between chlorpromazine use $(n=55)$ and mortality in hospitalized COVID-19 adult patients. Collectively, these two reports suggest that the use of antipsychotic drugs (haloperidol and chlorpromazine) might not be associated with the reduced risk of intubation or death in COVID-19 patients. As aforementioned, the use of antipsychotics was associated with the mortality of COVID-19 patients [29]. Furthermore, the use of antipsychotic drugs could cause extrapyramidal side effects due to potent dopamine $D_{2}$ receptor antagonism (Table 1) [7, 33]. It is, therefore, unlikely that the use of antipsychotic drugs should be recommended for the treatment of COVID-19 patients.

\section{MECHANISMS OF ACTION OF FLUVOXAMINE AND OTHER ANTIDEPRESSANTS Inhibition of serotonin transporter}

The primary action of all antidepressants, such as SSRIs and SNRIs, is serotonin transporter inhibition in the brain, resulting in increasing levels of serotonin in the synaptic cleft. The human platelets have a high density of serotonin transporter [34-36]. Through serotonin transporter inhibition in the platelets by SSRIs or SNRIs, these antidepressants could reduce platelet aggregation, contributing to their effects [37]. Preclinical and clinical studies show that SSRIs or SNRIs have anti-inflammatory effects in rodents and depressed patients [38-42]. Therefore, antidepressants can possibly have anti-inflammatory effects through serotonin transporter inhibition (Fig. 2). It is also reported that fluvoxamine attenuates inflammation on injured striatal neurons by increasing anti-inflammatory cytokines while decreasing 


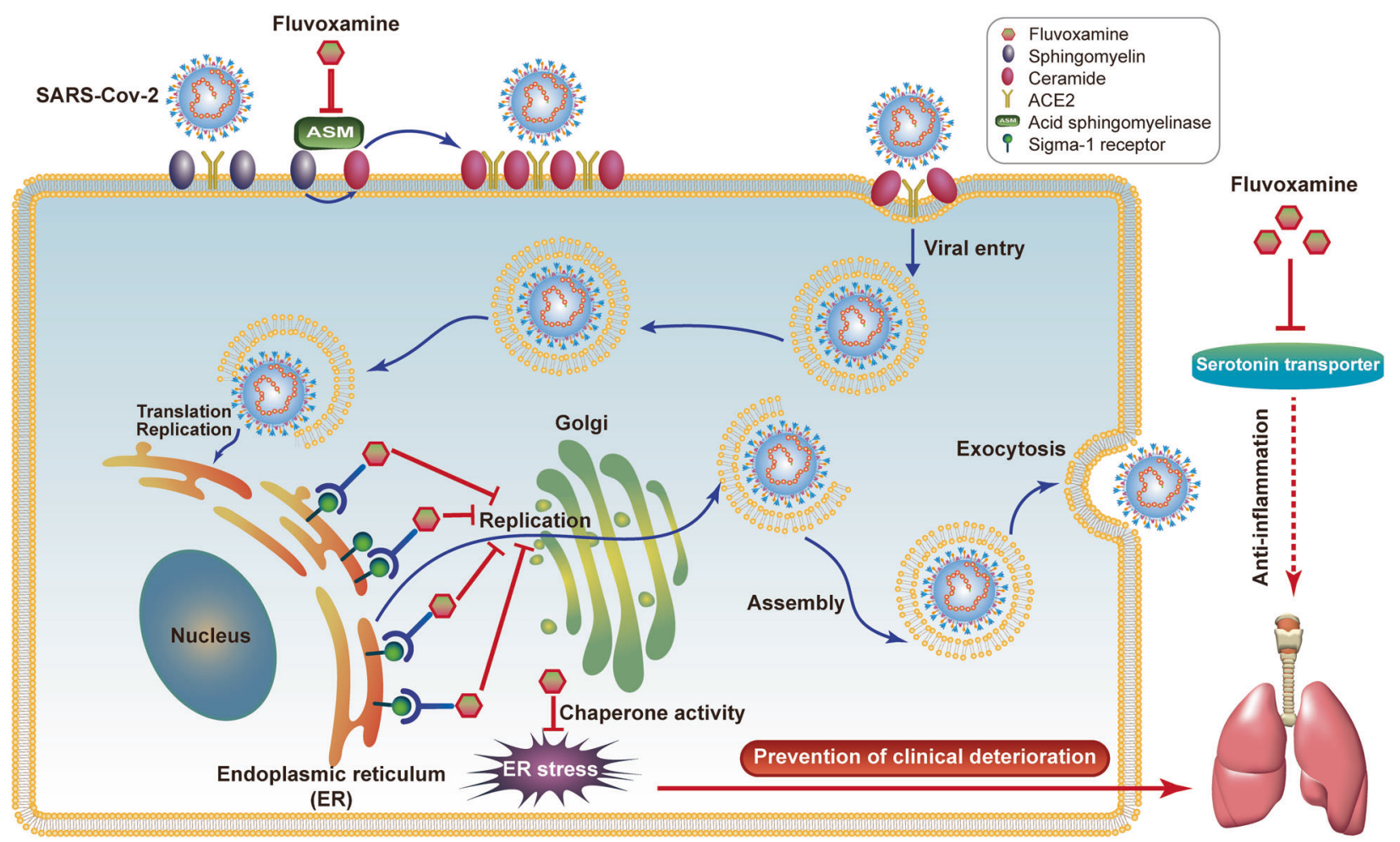

Fig. 2 Proposed biological mechanisms of fluvoxamine in the treatment of COVID-19 patients. SARS-CoV-2 binds to ACE2 receptor on the cells, resulting in acid sphingomyelinase (ASM) activation, converting sphingomyelin to ceramide. The ASM/ceramide system can facilitate viral entry. Antidepressants, such as fluvoxamine, inhibit ASM and ceramide-enriched membrane domain formation, resulting in decreased viral entry. Sigma-1 receptor plays a role in the SARS-CoV-2 replication. Through sigma-1 receptor chaperone activity, the sigma-1-receptor agonist fluvoxamine may attenuate SARS-CoV-2 replication and SARS-CoV-2 replication-induced ER stress in cells, resulting in a blockade against inflammatory events (i.e., cytokine storm). Moreover, fluvoxamine has anti-inflammatory effects by serotonin transporter inhibition in the body. Thus, early intervention using fluvoxamine may block or delay clinical deterioration in COVID-19 patients. A slight modification with Fig. 1 in the ref. [22]. Some materials of the figure have been designated using resources from Freepik.com.

pro-inflammatory cytokines in the brain of Parkinson's disease model [43]. Furthermore, fluvoxamine inhibits carrageenaninduced inflammation in rat paw edema [44] and fluvoxamine attenuated experimental autoimmune encephalomyelitis severity in a rat model of multiple sclerosis [45]. Collectively, it seems that fluvoxamine has potent anti-inflammatory effects in vitro and in vivo models.

The lung has a high expression of the serotonin transporter in rodents and humans [46-48], suggesting that potent vasoconstrictor serotonin bioavailability is predominantly regulated by the serotonin transporter in the lung endothelium [49]. Therefore, antidepressants, such as SSRIs and SNRIs, may influence COVID-19 patients' lung function. However, further study is needed.

Although all antidepressants can block the body's serotonin transporter, they did not show similar beneficial effects for COVID-19 patients. Therefore, it is unlikely that serotonin transporter inhibition by fluvoxamine may play a major role in its beneficial effects for COVID-19 patients. However, antiinflammatory effects of serotonin transporter inhibition may, in part, play a role in its beneficial effects (Fig. 2). A recent observational study showed that treatment with SSRIs such as sertraline, paroxetine, fluvoxamine, and fluoxetine showed antidepressant effects in patients $(n=60)$ with a post-COVID19 depression [50], suggesting the potential use of SSRIs in the treatment of post-COVID-19 depression.

\section{Sigma-1 receptor}

Role of sigma-1 receptor in the replication of SARS-CoV-2. In 2013, Friesland et al. [51] reported the endoplasmic reticulum (ER) protein sigma-1 receptor discovery as a cellular factor, mediating the early steps of viral RNA replication. The sigma-1 receptor expression is not rate-limiting for persistent hepatitis $C$ virus (HCV) RNA replication. However, it is rate-limiting for HCV RNA replication without impairing primary translation [51]. Thus, the sigma-1 receptor may be essential for virus replication at the earlystage of virus infection [52].

A recent study using the SARS-CoV-2 human protein-protein interaction map identified 332 high-confidence protein-protein interactions between SARS-CoV-2 and human proteins [53]. A number of compounds for sigma-1 and sigma-2 receptors were identified as promising inhibitors for SARS-CoV-2 replication [53]. Subsequently, the same group revealed the sigma-1 receptor (encoded by SIGMAR1) as a functional host dependency factor for SARS-CoV-2. Knockout (KO) or SIGMAR1 knockdown produced robust reductions in SARS-CoV-2 replication, indicating the sigma1 receptor's key role in SARS-CoV-2 replication [54]. Sigma-1 receptor is known to be enriched in lipid rafts colocalized with viral replicate proteins, such as non-structural protein 6 (NSP6). Taken together, sigma- 1 receptor might interfere with the early steps of virus-induced host cell reprogramming [55]. Moreover, through the chaperone activity, sigma-1 receptor agonists may protect against mitochondrial damage and ER stress in response to SARS-CoV-2 infection [56]. Therefore, sigma-1 receptor ligands could likely be useful for an early intervention for COVID-19 patients $[55,56]$. However, which pharmacological activity (i.e., agonist or antagonist) of sigma-1 receptor ligands is responsible for the SARS-CoV-2 replication activity remains uncertain [7].

Sigma-1 receptor and antidepressants. In 1996, our group reported the binding affinity of SSRIs for the sigma-1 receptor 
(Table 1) [57]. Some SSRIs, such as fluvoxamine, sertraline, fluoxetine, and citalopram, have a high to moderate affinity for sigma-1 receptors in the rat brain (Table 1). In contrast, the SSRI paroxetine, tricyclic antidepressants (imipramine and desipramine), SNRIs (duloxetine, venlafaxine, and milnacipran), and mirtazapine were very weak for the sigma-1 receptor (Table 1). This study suggests that the sigma- 1 receptor may play a role in the mechanisms of action of some SSRIs, such as fluvoxamine, with high affinity. The sigma-1 receptor cloned by Hanner et al. [58] shared homology with fungal proteins involved in sterol synthesis. Subsequently, Hayashi and Su [59] reported that it could function as a novel ER molecular chaperone, regulating a variety of cellular functions. Sigma-1 receptor agonists (i.e., fluvoxamine and fluoxetine) promote the sigma-1 receptor dissociation from another ER chaperone, binding immunoglobulin protein (BiP)/GRP78 (glucose-regulated protein 78), resulting in sigma-1 receptor chaperone activity in the cells. In contrast, sigma-1 receptor antagonists (i.e., haloperidol, NE-100) reinforce the association, blocking the action of sigma-1-receptor agonists $[59,60]$. Thus, sigma- 1 receptor agonists can produce chaperone activity, resulting in the protection against ER stress associated with a number of diseases.

Subsequent studies suggest that fluvoxamine is a potent agonist for sigma-1 receptor. In the assay, fluvoxamine, fluoxetine, and escitalopram significantly potentiated nerve growth factor (NGF)-induced neurite outgrowth in PC12 cells, and these SSRIs' effects were antagonized by selective sigma- 1 receptor antagonist NE-100 (Table 1) [61-63]. Moreover, the effects of fluvoxamine and fluoxetine on NGF-induced potentiation of neurite outgrowth were antagonized by sertraline, suggesting that sertraline may be a sigma-1 receptor antagonist (Table 1) [63]. A positron emission tomography using $\left[{ }^{11} \mathrm{C}\right] \mathrm{SA} 4503$ study showed that fluvoxamine binds to the sigma-1 receptor in the intact human brain at therapeutic doses [64]. Collectively, fluvoxamine is a likely unique SSRI with potent sigma-1 receptor agonism [65-68].

In 2019, Rosen et al. [69] demonstrated sigma-1 receptor's essential role in inflammation and sepsis mouse models. The mortality (62\%) of sigma-1 receptor KO mice post-injection of lipopolysaccharide (LPS: $5 \mathrm{mg} / \mathrm{kg}$ ) was significantly higher than that $(9 \%)$ of wild-type mice. Furthermore, serum levels of proinflammatory cytokines [i.e., IL-6, tumor necrosis factor-a (TNFa)] in $\mathrm{KO}$ mice after LPS $(5 \mathrm{mg} / \mathrm{kg})$ injection were significantly higher than those of wild-type mice [69]. The data suggest that sigma-1 receptor plays a key role in systemic inflammation and cytokine production. Interestingly, treatment with fluvoxamine could protect against LPS (6 mg/kg)-induced lethal septic shock [69]. Collectively, it is likely that the potent sigma-1 receptor agonist fluvoxamine might ameliorate ER stress-associated inflammatory events (i.e., cytokine storm) due to SARS-CoV-2 replication (Fig. 2) [7, 22].

As mentioned above, haloperidol or sertraline use may not be associated with the risk of intubation or death in COVID-19 hospitalized adult patients, although the sample size is too small $[21,31]$. Since haloperidol and sertraline are sigma-1 receptor antagonists (Table 1), sigma-1 receptor antagonists seem to not have beneficial effects in COVID-19 patients. However, further study is needed.

Given the key role of the chaperone activity by sigma-1 receptor agonist in SARS-CoV-2 replication, it is possible that the SSRIs (i.e., fluvoxamine, fluoxetine, escitalopram) with sigma-1 receptor agonisms could be COVID-19 prophylactic drugs. Current data of fluoxetine and escitalopram for COVID-19 are from an observational study in France [21].

Interaction of steroids with sigma-1 receptor. Steroids are synthesized from cholesterol in the CNS and peripheral nervous system. Pregnenolone (PREG) synthesized from cholesterol is converted into 17a-hydroxypregnenolone and then dehydroepiandrosterone
(DHEA). Both PREG and DHEA are found, in part, as sulfate esters (PREG-S and DHEA-S). DHEA is metabolized to testosterone, the key male sex hormone, and PREG is converted into progesterone [70]. DEHA, the most abundant endogenous steroid, is a sigma-1 receptor agonist with moderate affinity, whereas progesterone and testosterone are sigma-1 receptor antagonists.

It is well known that illness severity in male COVID-19 patients is consistently higher than that of women [71, 72]. There are sexspecific mechanisms, including hormone-related expression of genes encoding for SARS-CoV-2 entry receptors (i.e., angiotensinconverting enzyme 2 (ACE2) receptor) and immune responses to SARS-CoV-2 [73]. Being known to regulate the immune system, sex steroids, such as testosterone, estradiol, and progesterone, may play a role in gender differences in clinical courses of SARS-CoV-2infected people.

A case-controlled study in Italy showed that lower testosterone levels in male COVID-19 patients $(n=286)$ were associated with a higher risk of ICU admission and death outcomes [74]. Subsequently, a single-center cohort study showed that lower testosterone levels during hospitalization were associated with increased disease severity and inflammation in men with severe COVID-19 $(n=66)$ [75]. In this study, testosterone levels were inversely associated with levels of IL-6, C-reactive protein (CRP), interleukin 1 receptor antagonist, hepatocyte growth factor, and interferon $\gamma$-inducible protein 10. In contrast, estradiol and insulin-like growth factor 1 (IGF1) were not associated with the severity in men with COVID-19. There were no changes in testosterone, estradiol, and IGF-1 in women with and without severe COVID-19. Furthermore, male COVID-19 patients with a severe course of infection had lower serum testosterone levels [75], which were also associated with elevated CRP and IL-6, lower cholesterol levels, and increased morbidity and mortality [75]. Collectively, lower testosterone levels in men with COVID-19 are linked to more advanced immune activation, increasing the risk for ICU admission or death. The underlying mechanisms for the association between low testosterone and severe clinical course in male COVID-19 patients remain unknown. Although testosterone is an antagonist with moderate affinity for the sigma-1 receptor, whether sigma- 1 receptor plays a role in the action of testosterone for COVID-19 remains unclear.

Progesterone's anti-inflammatory actions are well recognized. It has various alleviating effects, from SARS-CoV-2 entry to recovery: reversing hypoxia, stabilizing blood pressure, controlling thrombosis, balancing electrolytes, reducing the viral load, immune response regulation, damage repair, and debris clearance among others $[76,77]$. Hence, progesterone use for COVID-19 patients is recommended [77]. A pilot randomized open-label controlled study showed beneficial effects of progesterone $(100 \mathrm{mg}$ twice daily for up to 5 days) in moderate to severe COVID-19 hospitalized male patients [78]. Although progesterone is an antagonist with a high affinity for the sigma-1 receptor, whether sigma-1 receptor plays a role in the action of progesterone for COVID-19 remains unclear.

DHEA (or DHEA-S), a testosterone precursor, is a sigma-1 receptor agonist $[62,79]$. PREG (or PREG-S), a progesterone precursor, is also a weak agonist for sigma-1 receptor. Therefore, it is of interest to measure blood levels of these steroids in COVID-19 patients.

\section{Acid sphingomyelinase (ASM)}

The acid sphingomyelinase (ASM) and ceramide play key roles in bacterial and viral infections. ASM is a glycoprotein that functions as a lysosomal hydrolase, catalyzing sphingomyelin degradation to phosphorylcholine and ceramide (Fig. 2) [80-82]. Ceramide is also known to facilitate viral entry despite sphingosine's blockage. Thus, ASM is essential for ceramide generation. Its functional inhibition can reduce virus entry into the epithelial cells. SARSCoV-2 activates the ASM/ceramide system, resulting in the formation of ceramide-enriched membrane domains that serve viral entry and infection of clustering ACE2, the cellular receptor of SARS-CoV-2 [83]. 


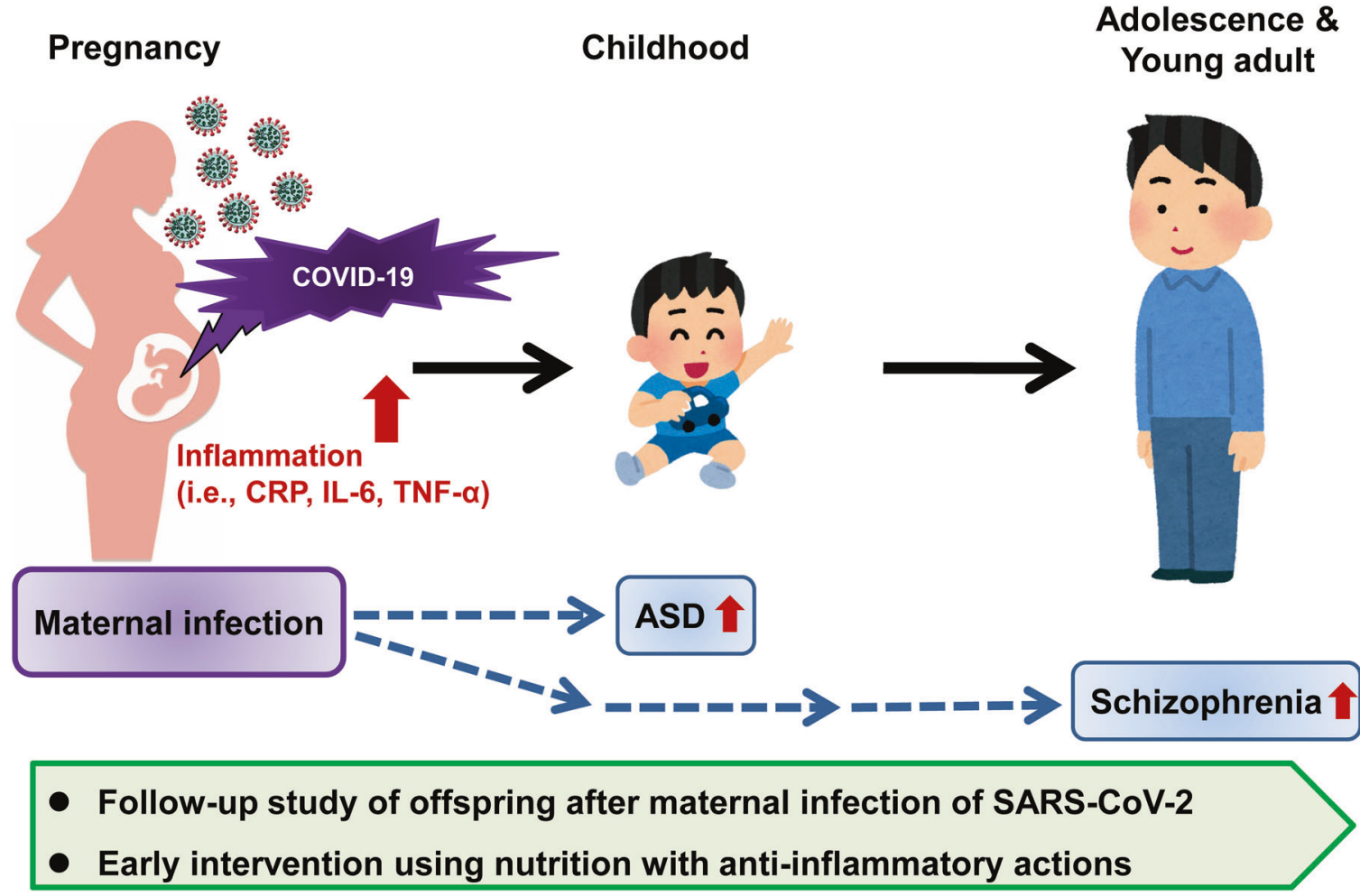

Fig. 3 The risk for neuropsychiatric disorders in offspring after maternal COVID-19 infection. Maternal infection by SARS-CoV-2 causes inflammatory events in pregnant women, resulting in higher levels of inflammatory biomarkers (i.e., CRP, IL-6, and TNF- $\alpha$ ) in the blood and tissues. Given the role of maternal immune activation in the risk of neuropsychiatric disorders, such as ASD and schizophrenia in offspring, a follow-up study of COVID-19-infected pregnant women and their children is needed. Furthermore, early intervention using nutrition with antiinflammatory actions may be needed to block the onset of neuropsychiatric disorders. A slight modification with Fig. 1 in the ref. [113]. Some materials of the figure have been designated using resources from Freepik.com and www.irasutoya.com.

Many antidepressants, such as fluoxetine, sertraline, paroxetine, and amitriptyline, are reported to inhibit ASM activity, suggesting a possible role of ASM in the effects of antidepressants [84-86]. Antidepressants (i.e., amitriptyline, imipramine, fluoxetine, sertraline, and escitalopram) with ASM inhibition prevented the infection of cultured cells or freshly isolated human nasal epithelial cells with SARS-CoV-2 (Table 1) $[87,88]$. Fluvoxamine is also known to be an inhibitor of ASM [89].

A recent observational multicenter study $(n=2846)$ showed association ( $\mathrm{HR}=0.71,95 \% \mathrm{Cl}=0.58-0.87, P<0.01)$ between the use of functional inhibitors of ASM and reduced risk of intubation or death among severe COVID-19 hospitalized patients $(n=277)$ [90]. Among the antidepressants, escitalopram use was significantly associated with a reduced risk of severe clinical stage [90]. However, other antidepressants, including amitriptyline, clomipramine, duloxetine, fluoxetine, paroxetine, and sertraline (Table 1), did not reach statistical significance, possibly due to restricted statistical power [90]. As mentioned above, fluvoxamine was not included.

The typical antipsychotic drug chlorpromazine is an ASM inhibitor (Table 1), and chlorpromazine blocked SARS-CoV-2 replication in human cells [91]. Hoertel et al. [32] reported an observational study of typical antipsychotic drug chlorpromazine in COVID-19 hospitalized patients $(n=14,340)$ [32]. In the primary analysis, there was no significant association $(\mathrm{HR}=2.01,95 \% \mathrm{Cl}=$ $0.75-5.40, P=0.163)$ between chlorpromazine use $(n=55)$ and mortality in hospitalized COVID-19 adult patients. Since chlorpromazine is an ASM functional inhibitor [32], ASM inhibition unlikely plays a major role in the protective effects for the risk of death in COVID-19 patients. Nonetheless, further randomized, double-blind study using a large sample size is needed.
Considering the role of sigma-1 receptor and ASM in biological actions of SARS-CoV-2 in cells (Fig. 2) [92], escitalopram may be a prophylactic or therapeutic drug for SARS-CoV-2-infected patients. However, a further clinical study using a large sample size is needed.

\section{Other mechanisms}

Melatonin. Melatonin is naturally synthesized in the pineal gland and immune cells from the amino acid tryptophan. It may be a potential drug for COVID-19, since it has anti-inflammatory, immunomodulatory, and antioxidant mechanisms [93, 94]. It is proposed that increased melatonin levels by cytochrome P450 enzyme CYP1A2 inhibition by fluvoxamine may play a role in the anti-inflammatory effects of fluvoxamine $[37,95]$.

Phospholipidosis. The inhibition of phospholipid production is suggested to be associated with the inhibition of coronavirus replication [96]. Among the many candidates investigated, sertraline and chlorpromazine were examples of high phospholipidosisinducing drugs for SARS-CoV-2 in vitro [12]. Unfortunately, all candidates, including sertraline, were not efficacious in in vivo model. However, the only FDA-approved remdesivir showed beneficial effects in the same model. These findings strongly suggest that candidates discovered in in vitro assay do not translate in vivo. In the observational studies in France, sertraline or haloperidol use was not associated with reduced risk of intubation or death [21, 31]. Collectively, it is unlikely that phospholipid production-inhibiting compounds may be potential prophylactic or therapeutic drugs for COVID-19.

Lysosomal trafficking. Other mechanisms include reduction in decreased mast cell degranulation and modulation with lysosomal 
viral trafficking [37]. In a recent study, a sub-therapeutic concentration $(80 \mathrm{nM})$ of fluvoxamine results in a significant rearrangement of membrane trafficking in a human cell line, enhancing endocytic uptake of SARS-CoV-2 spike proteins [97].

In a new study, antidepressants (i.e., fluvoxamine, fluoxetine, citalopram, paroxetine, venlafaxine, reboxetine, clomipramine, and imipramine) had antiviral effects in SARS-CoV-2-infected cells [98]. However, the precise mechanisms underlying their antiviral effects remain unknown.

\section{PREGNANT WOMEN \\ Pregnant women infected with SARS-CoV-2 and mental health in offspring}

Epidemiological studies suggest that maternal immune activation (MIA), such as maternal infection, might be associated with the risk for neuropsychiatric disorders, such as autism spectrum disorder (ASD) and schizophrenia in offspring [99-101]. For example, a population-based birth cohort study (born in 1959-1966) showed that the risk of schizophrenia was increased sevenfold for influenza exposure during the first trimester, but not the second or third trimester [102]. In a study using all children born in Denmark in 1980-2005, hospital admission due to maternal viral and maternal bacterial infections in the first and second trimesters, respectively, were associated with the onset of ASD in the offspring [103]. Collectively, maternal infection during the first trimester is possibly a risk factor for ASD and schizophrenia in offspring.

During the COVID-19 pandemic, the number of SARS-CoV-2infected pregnant women has been increasing worldwide. There are several reports showing higher levels of inflammatory biomarkers such as CRP in pregnant women with COVID-19 [104-106], suggesting MIA in pregnant women with COVID-19. Considering the risk for maternal infection on neuropsychiatric disorders in offspring, offspring follow-up after maternal infection by SARS-CoV-2 is important (Fig. 3). It is of great interest to compare the incidence of neuropsychiatric disorders in offspring of pregnant women with or without COVID-19.

It is shown that pregnant and recently pregnant women are at an increased risk for severe clinical course from COVID-19 than nonpregnant women $[107,108]$. In the multinational cohort study of pregnant women $(n=2130)$ in 18 countries, women with COVID-19 were at higher risk for preeclampsia/eclampsia [relative risk $(R R)=1.76 ; 95 \% \mathrm{Cl}=1.27-2.43]$, severe infections $(R R=3.38$, $95 \% \quad \mathrm{Cl}=1.63-7.01), \quad \mathrm{ICU}$ admission $(\mathrm{RR}=5.04,95 \% \quad \mathrm{Cl}=$ 3.13-8.10), maternal mortality $(\mathrm{RR}=22.3,95 \% \mathrm{Cl}=2.88-172)$, preterm ( $\mathrm{RR}=1.59,95 \% \mathrm{Cl}=1.30-1.94)$ and medically indicated preterm births $(\mathrm{RR}=1.97,95 \% \mathrm{Cl}=1.56-2.51)$, severe neonatal morbidity index $(\mathrm{RR}=2.66,95 \% \mathrm{Cl}=1.69-4.18)$, and severe perinatal morbidity and mortality index $(\mathrm{RR}=2.14,95 \% \mathrm{Cl}=$ 1.66-2.75) [108]. More than one half of pregnant women with COVID-19 are asymptomatic or mild. However, a part of them is converted to severe stages. Therefore, vaccination for SARS-CoV-2 in pregnant women is important to prevent clinical deterioration post-infection. Although the safety of the mRNA COVID-19 vaccine in pregnant women was reported [109], maternal vaccination effects on offspring remain unclear. Therefore, following up their children postdelivery from mothers with COVID-19 is important (Fig. 3).

Preclinical and clinical studies suggest that nutritional intervention with anti-inflammatory compounds (i.e., sulforaphane, omega-3 polyunsaturated fatty acids, choline, and vitamin D) may prevent the onset of neuropsychiatric disorders in offspring after MIA [110-116]. Collectively, we suggest that nutritional intervention may be a useful approach for the prevention of neuropsychiatric disorders in offspring after maternal SARS-CoV-2 infection (Fig. 3) [113].
The use of antidepressants in pregnant women with COVID-19 Increasing evidence suggests that the use of antidepressants during pregnancy might be associated with the risk of ASD in offspring [117-119]. Conversely, in a recent systematic umbrella review, maternal use of antidepressants appears to be safe for psychiatric disorder treatment [120], although further study is needed. A recent meta-analysis showed that neither psychiatric control or discordant sibling designs supported the association between prenatal antidepressant exposure and ASD [121].

A recent meta-analysis of pregnant women during the COVID19 pandemic showed high prevalence of depression and anxiety in pregnant women [122]. According to the NIH COVID-19 Treatment Guideline, fluvoxamine is not thought to increase the risk of congenital abnormalities. However, data on fluvoxamine use during pregnancy are limited. The risk of fluvoxamine use should be balanced with potential benefit. If pregnant women with COVID-19 use antidepressants as a treatment for their mood disorders or prophylactic treatment for the clinical deterioration of COVID-19, a mental health follow-up for the offspring is also important.

\section{CONCLUSION}

As we discussed in this article, the mechanisms of action of fluvoxamine for COVID-19 are complex. Given the roles of sigma-1 receptor in the early-stage of virus replication and ASM in virus entry, fluvoxamine would be a potential prophylactic drug, reducing clinical deterioration in COVID-19 patients. Importantly, it should be taken in persons with COVID-19 as quickly as possible after SARS-CoV-2 infection confirmation.

From the limited clinical data, fluvoxamine may be the most attractive candidate for early-stage COVID-19 patients. However, further randomized, multicenter, double-blind study using a large sample size is needed. Fluvoxamine has favorable safety profiles, widespread availability, and is very low cost administered orally and used for children and adolescents [22]. If fluvoxamine is used in the treatment of pregnant women with COVID-19, follow-up for the offspring is important. Several SARS-CoV-2-neutralizing monoclonal antibodies for mild to moderate symptoms in high-risk COVID-19 patients were approved [123]. Recently, Merck Sharp and Dohme reported that the novel oral antiviral drug molnupiravir reduced the risk of admission to hospital or death by around $50 \%$ in non-hospitalized adults [124]. It is possible that a combination of fluvoxamine with neutralizing monoclonal antibodies or molnupiravir may be more effective [125], although further study is needed. Finally, a cheap, widely available fluvoxamine would be a "gamechanger" for people with COVID-19.

\section{REFERENCES}

1. Siddiqi HK, Mehra MR. COVID-19 illness in naïve and immunosuppressed states: a clinical-therapeutic staging proposal. J Heart Lung Transpl. 2020;39:405-7.

2. Wu Y, Xu X, Chen Z, Duan J, Hashimoto K, Yang L, et al. Nervous system involvement after infection with COVID-19 and other coronaviruses. Brain Behav Immun. 2020;87:18-22.

3. Li Z, Ge J, Yang M, Feng J, Qiao M, Jiang R, et al. Vicarious traumatization in the general public, members, and non-members of medical teams aiding in COVID19 control. Brain Behav immun. 2020:88:916-9.

4. Zhang J, Xu D, Xie B, Zhang Y, Huang H, Liu H, et al. Poor-sleep is associated with slow recovery from lymphopenia and an increased need for ICU care in hospitalized patients with COVID-19: A retrospective cohort study. Brain Behav Immun. 2020;88:50-8.

5. Yuan K, Gong YM, Liu L, Sun YK, Tian SS, Wang YJ, et al. Prevalence of posttraumatic stress disorder after infectious disease pandemics in the twenty-first century, including COVID-19: a meta-analysis and systematic review. Mol Psychiatry. 2021;26:4982-98.

6. Shi L, Lu ZA, Que JY, Huang XL, Lu QD, Liu L, et al. Long-term impact of COVID19 on mental health among the general public: a nationwide longitudinal study in China. Int J Environ Res Public Health. 2021;18:8790. 
7. Hashimoto K. Repurposing of CNS drugs to treat COVID-19 infection: targeting the sigma-1 receptor. Eur Arch psychiatry Clin Neurosci. 2021;271:249-58.

8. Cavasotto CN, Di Filippo Jl. In silico drug repurposing for COVID-19: targeting SARS-CoV-2 proteins through docking and consensus ranking.Mol Inform. 2021;40:e2000115.

9. Ng YL, Salim CK, Chu JJH. Drug repurposing for COVID-19: approaches, challenges and promising candidates. Pharm Ther. 2021;228:107930.

10. Venkatesan P. Repurposing drugs for treatment of COVID-19. Lancet Respir Med. 2021;9:e63.

11. Zhang J, Xie B, Hashimoto K. Current status of potential therapeutic candidates for the COVID-19 crisis. Brain Behav Immun. 2020;87:59-73.

12. Tummino TA, Rezelj VV, Fischer B, Fischer A, O'Meara MJ, Monel B, et al. Druginduced phospholipidosis confounds drug repurposing for SARS-CoV-2. Science. 2021;373:541-7.

13. Srivastava K, Singh MK. Drug repurposing in COVID-19: a review with past, present and future. Metab Open. 2021;12:100121.

14. Self WH, Semler MW, Leither LM, Casey JD, Angus DC, Brower RG, et al. Effect of hydroxychloroquine on clinical status at 14 days in hospitalized patients with COVID-19: a randomized clinical trial. JAMA. 2020;324:2165-76.

15. Mitjà $O$, Corbacho-Monné $M$, Ubals $M$, Alemany $A$, Suñer $C$, Tebé $C$, et al. $A$ cluster-randomized trial of hydroxychloroquine for prevention of Covid-19. N Eng J Med. 2021;384:417-27.

16. Reis G, Moreira Silva EADS, Medeiros Silva DC, Thabane L, Singh G, Park JJH, et al. Effect of early treatment with hydroxychloroquine or lopinavir and ritonavir on risk of hospitalization among patients with COVID-19: the TOGETHER randomized clinical trial. JAMA Netw Open. 2021;4:e216468.

17. López-Medina E, López $P$, Hurtado IC, Dávalos DM, Ramirez O, Martínez E, et al. Effect of ivermectin on time to resolution of symptoms among adults with mild COVID-19: a randomized clinical trial. JAMA. 2021;325:1426-35.

18. Kow CS, Merchant HA, Mustafa ZU, Hasan SS. The association between the use of ivermectin and mortality in patients with COVID-19: a meta-analysis. Pharm Rep. 2021;73:1473-9.

19. Roman YM, Burela PA, Pasupuleti V, Piscoya A, Vidal JE, Hernandez AV. Ivermectin for the treatment of COVID-19: a systematic review and meta-analysis of randomized controlled trials. Clin Infect Dis. 2021. ciab591.

20. Lenze E, Mattar C, Zorumski CF, Zorumski CF, Stevens A, Schweiger J, et al. Fluvoxamine vs placebo and clinical deterioration in outpatients with symptomatic COVID-19. A randomized clinical trial. JAMA. 2020;324:2292-300.

21. Hoertel N, Sánchez-Rico M, Vernet R, Beeker N, Jannot AS, Neuraz A, et al. Association between antidepressant use and reduced risk of intubation or death in hospitalized patients with COVID-19: results from an observational study. Mol Psychiatry. 2021;26:5199-212.

22. Hashimoto $Y$, Suzuki T, Hashimoto K. Old drug fluvoxamine, new hope for COVID-19. Eur Arch Psychiatry Clin Neurosci. 2021. https://doi.org/10.1007/ s00406-021-01326-z.

23. Seftel D, Boulware DR. Prospective cohort of fluvoxamine for early treatment of coronavirus disease 19. Open Forum Infect Dis. 2021;8:ofab050.

24. Reis G, Moreira Silva EADS, Medeiros Silva DC, Thabane L, Milagres AC, Ferreira TS, et al. Effect of early treatment with fluvoxamine on risk of emergency care and hospitalization among patients with COVID-19: the TOGETHER randomized, platform clinical trial. Lancet Glob Health. 2021. https://doi.org/10.1016/S2214109X(21)00448-4.

25. Sax PE. Could this be our first effective, inexpensive, widely available outpatient treatment for COVID-19? NEJM J Watch. 2021. https://blogs.jwatch.org/hiv-idobservations/index.php/could-this-be-our-first-effective-inexpensive-widelyavailable-outpatient-treatEl-battrawy.Iment-for-covid-19/2021/08/12/.

26. Calusic M, Marcec R, Luksa L, Jurkovic I, Kovac N, Mihaljevic S, et al. Safety and efficacy of fluvoxamine in COVID-19 ICU patients: an open label, prospective cohort trial with matched controls. Bri J Clin Pharm. 2021. https://doi.org/ 10.1111/bcp.15126.

27. Oskotsky T, Maric I, Tang A, Oskotsky B, Wong RJ, Aghaeepour N, et al. Mortality risk among patients with COVID-19 prescribed selective serotonin reuptake inhibitor antidepressants. JAMA Netw Open. 2021;4:e2133090.

28. Fei L, Santarelli G, D'Anna G, Moretti S, Mirossi G, Patti A, et al. Can SSRI/SNRI antidepressants decrease the 'cytokine storm' in the course of COVID19 pneumonia? Panminerva Med. 2021. https://doi.org/10.23736/S00310808.21.04436-0.

29. Vai B, Mazza MG, Delli Colli C, Foiselle M, Allen B, Benedetti F, et al. Mental disorders and risk of COVID-19-related mortality, hospitalization, and intensive care unit admission: a systematic review and meta-analysis. Lancet Psychiatry. 2021:8:797-812.

30. El-Battrawy I, Nuñez-Gil IJ, Abumayyaleh M, Estrada V, Manuel Becerra-Muñoz V Uribarri A, et al. COVID-19 and the impact of arterial hypertension- An analysis of the international HOPE COVID-19 Registry (Italy-Spain-Germany). Eur J Clin Invest. 2021:51:e13582.
31. Hoertel N, Sánchez-Rico M, Vernet R, Jannot AS, Neuraz A, Blanco C, et al. Observational study of haloperidol in hospitalized patients with COVID-19. PLoS ONE. 2021;16:e0247122.

32. Hoertel N, Sánchez-Rico M, Vernet R, Jannot AS, Neuraz A, Blanco C, et al Observational study of chlorpromazine in hospitalized patients with COVID-19. Clin Drug Invest. 2021;41:221-33.

33. Tam SW, Cook L. Sigma opiates and certain antipsychotic drugs mutually inhibit $(+)-\left[{ }^{3} \mathrm{H}\right] \mathrm{SKF} 10,047$ and $\left[{ }^{3} \mathrm{H}\right]$ haloperidol binding in guinea pig brain membranes. Proc Natl Acad Sci USA. 1984;81:5618-21.

34. Hashimoto $K$, Goromaru T. High-affinity binding of $\left[{ }^{3} \mathrm{H}\right] 6$-nitroquipazine to 5-hydroxytryptamine transporter in human platelets. Eur J Pharm. 1990;187:295-302.

35. Maurer-Spurej E, Pittendreigh C, Solomons K. The influence of selective serotonin reuptake inhibitors on human platelet serotonin. Thromb Haemost. 2004;91:119-28.

36. Jedlitschky G, Greinacher A, Kroemer HK. Transporters in human platelets: physiologic function and impact for pharmacotherapy. Blood. 2012;119:3394-402.

37. Sukhatme VP, Reiersen AM, Vayttaden SJ, Sykhatme W. Fluvoxamine: a review of its mechanisms of actions and its role in COVID-19. Front Pharm. 2021;12:652688

38. Tynan RJ, Weidenhofer J, Hinwood M, Cairns MJ, Day TA, Walter FR. A comparative examination of the antiinflammatory effects of SSRI and SNRI antidepressants on LPS stimulated microglia. Brain Behav Immun. 2012;26:469-79.

39. Ohgi Y, Futamura T, Kikuchi T, Hashimoto K. Effects of antidepressants on alterations in serum cytokines and depressive-like behavior in mice after lipopolysaccharide administration. Pharm Biochem Behav. 2013;103:853-9.

40. Dong C, Zhang JC, Yao W, Ren Q, Yang C, Ma M, et al. Effects of escitalopram, Rcitalopram, and reboxetine on serum levels of tumor necrosis factor-alpha, interleukin-10, and depression-like behavior in mice after lipopolysaccharide administration. Pharm Biochem Behav. 2016;144:7-12.

41. Hashimoto K. Inflammatory biomarkers as differential predictors of antidepressant response. Int J Mol Sci. 2015;16:7796-801.

42. Wang L, Wang R, Liu L, Qiao D, Baldwin DS, Hou R. Effects of SSRIs on peripheral inflammatory markers in patients with major depressive disorder: A systematic review and meta-analysis. Brain Behav Immun. 2019;79:24-38.

43. Dallé $E$, Daniels WM, Mabandia MV. Fluvoxamine maleate normalizes striatal neuronal inflammatory cytokine activity in a Parkinsonian rat model associated with depression. Behav Brain Res. 2017;316:189-96.

44. Rafiee L, Hajhashemi V, Javanmard SH. Fluvoxamine inhibits some inflammatory genes expression in LPS/stimulated human endothelial cells, U937 macrophages, and carrageenan-induced paw edema in rat. Iran J Basic Med Sci. 2016;19:977-84.

45. Ghareghani M, Zibara K, Sadeghi H, Dokoohaki S, Sadeghi H, Aryanpour R, et al. Fluvoxamine stimulates oligodendrogenesis of cultured neural stem cells and attenuates inflammation and demyelination in an animal model of multiple sclerosis. Sci Rep. 2017;7:4923.

46. Hashimoto $\mathrm{K}$, Goromaru T. High-affinity $\left[{ }^{3} \mathrm{H}\right] 6$-nitroquipazine binding to the 5-hydroxytryptamine transport system in rat lung. Biochem Pharm. 1991;41: 1679-82.

47. Hashimoto K, Inoue O, Suzuki K, Yamasaki T, Kojima M. Synthesis and evaluation of $\left[{ }^{11} \mathrm{C}\right]$ cyanoimipramine. Int J Rad Appl Instrum B. 1987;46:587-92.

48. Takano A, Suhara $T$, Sudo $Y$, Inoue $M$, Hashimoto $K$, Zhang MR, et al. Comparative evaluation of two serotonin transporter ligands in the human brain: $\left[{ }^{11} \mathrm{C}\right](+)$ McN5652 and $\left[{ }^{11} \mathrm{C}\right]$ cyanoimipramine. Eur J Nucl Med. 2002;29:1289-97.

49. Adnot S, Houssaini A, Abid S, Marcos E, Amsellem V. Serotonin transporter and serotonin receptors. Handb Exp Pharm. 2013;218:365-80.

50. Mazza MG, Zanardi R, Palladini M, Rovere-Querini P, Benedetti F. Rapid response to selective serotonin reuptake inhibitors in post-COVID depression. Eur Neuropsychopharmacol. 2021;54:1-6.

51. Friesland M, Mingorance L, Chung J, Chisari FV, Gastaminza P. Sigma-1 receptor regulates early steps of viral RNA replication at the inset of hepatitis $C$ virus infection. J Virol. 2013;87:6377-90.

52. Vasallo $C$, Gastaminza P. Cellular stress response in hepatitis $C$ virus infection: mastering a two-edged sword. Virus Res. 2015;209:100-17.

53. Gordon DE, Jang GM, Bouhaddou M, Xu J, Obernier K, White KM, et al. A SARSCoV-2 protein interaction map reveals targets for drug repurposing. Nature. 2020;583:459-68.

54. Gordon DE, Hiatt J, Bouhaddou M, Rezelj VV, Ulferts S, Braberg H, et al. Comparative host-coronavirus protein interaction networks reveal pan-viral disease mechanisms. Science. 2020;370:eabe9403.

55. Vela JM. Repurposing sigma-1 receptor ligands for COVID-19 therapy? Front Pharm. 2020;11:582310.

56. Brimson JM, Prasanth MI, Malar DS, Brimson S, Thitilertdecha P, Tencomnao T. Drugs that offer the potential to reduce hospitalization and mortality from SARS-CoV-2 infection: the possible role of the sigma-1 receptor and autophagy. Expert Opin Ther Targets. 2021;25:435-49. 
57. Narita N, Hashimoto K, Tomitaka S, Minabe Y. Interaction of selective serotonin reuptake inhibitors with subtypes of sigma receptors in rat brain. Eur J Pharm. 1996;307:117-9.

58. Hanner M, Moebius FF, Flandorfer A, Knaus HG, Striessnig J, Kempner E, et al. Purification, molecular cloning, and expression of the mammalian sigma ${ }^{-}$ binding site. Proc Natl Acad Sci USA. 1996;93:8072-7.

59. Hayashi T, Su TP. Sigma-1 receptor chaperones at the ER-mitochondrion interface regulate $\mathrm{Ca}^{2+}$ signaling and cell survival. Cell. 2007;131:596-610.

60. Hayashi T, Tsai SY, Mori T, Fujimoto M, Su TP. Targeting ligand-operated chaperone sigma-1 receptors in the treatment of neuropsychiatric disorders. Expert Opin Ther Targets. 2011;15:557-77.

61. Takebayashi M, Hayashi T, Su TP. Nerve growth factor-induced neurite sprouting in PC12 cells involves sigma-1 receptors: implications for antidepressants. J Pharm Exp Ther. 2002;303:1227-37.

62. Nishimura $\mathrm{T}$, Ishima $\mathrm{T}$, Iyo $\mathrm{M}$, Hashimoto $\mathrm{K}$. Potentiation of nerve growth factorinduced neurite outgrowth by fluvoxamine: role of sigma-1 receptors, $\mathbb{I P}_{3}$ receptors and cellular signaling pathways. PLoS ONE. 2008:3:e2558.

63. Ishima T, Fujita $Y$, Hashimoto K. Interactions of new antidepressants with sigma1 receptor chaperons and their potentiation of neurite outgrowth in PC12 cells. Eur J Pharm. 2014;727:167-73.

64. Ishikawa M, Ishiwata K, Ishii K, Kimura Y, Sakata M, Naganawa M, et al. High occupancy of sigma-1 receptors in the human brain after single oral administration of fluvoxamine: a positron emission tomography using $\left[{ }^{11} \mathrm{C}\right] \mathrm{SA} 4503$. Biol Psychiatry. 2007;62:878-83.

65. Hindmarch I, Hashimoto K. Cognition and depression: the effects of fluvoxamine, a sigma-1 receptor agonist, reconsidered. Hum Psychopharmacol. 2010;25:193-200.

66. Niitsu T, lyo $M$, Hashimoto K. Sigma-1 receptor agonists as therapeutic drugs for cognitive impairment in neuropsychiatric disorders. Curr Pharm Des. 2012;18:875-83.

67. Hashimoto K. Activation of sigma-1 receptor chaperone in the treatment of neuropsychiatric diseases and its clinical implication. J Pharm Sci. 2015;127:6-9.

68. Albayrak Y, Hashimoto K. Sigma-1 receptor agonists and their clinical implication in neuropsychiatric disorders. Adv Exp Med Biol. 2017;964:153-61.

69. Rosen DA, Seki SM, Fernández-Castañeda A, Beiter RM, Eccles JD, Woodfolk JA, et al. Modulation of the sigma-1 receptor-IRE1 pathway is beneficial in preclinical models of inflammation and sepsis. Sci Transl Med. 2019;11:eaau5266.

70. Hashimoto K. Sigma-1 receptor chaperone and brain-derived neurotrophic factor: emerging links between cardiovascular disease and depression. Prog Neurobiol. 2013;100:15-29.

71. Jin JM, Bai P, He W, Wu F, Liu XF, Han DM, et al. Gender differences in patients with COVID-19: Focus on severity and mortality. Front Public Health. 2020;8:152.

72. Gebhard C, Regitz-Zagrosek V, Neuhauser HK, Morgan R, Klein SL. Impact of sex and gender on COVID-19 outcomes in Europe. Biol Sex Differ. 2020;11:29.

73. Salonia A, Pontillo M, Capogrosso P, Gregori S, Tassara M, Boeri L, et al. Severely low testosterone in males with COVID-19: a case-control study. Andrology. 2021;9:1043-52.

74. Dhindsa S, Zhang N, McPhaul MJ, Wu Z, Ghoshal AK, Erlich EC, et al. Association of circulating sex hormones with inflammation and disease severity in patients with COVID-19. JAMA Netw Open. 2021;4:e2111398.

75. Lanser L, Burkert FR, Thommens L, Egger A, Hoermann G, Kaser S, et al. Testosterone deficiency is a risk factor for severe COVID-19. Front Endocrinol (Lausanne). 2021;12:694083.

76. Shah SB. COVID-19 and progesterone: Part 1. SARS-CoV-2, progesterone and its potential clinical use. Endcr Metab Sci. 2021;5:100110.

77. Shah SB. COVID-19 and progesterone: Part 2. Unraveling high severity, immunity patterns, immunity grading, progesterone and its potential clinical use. Endcr Metab Sci. 2021;5:100110.

78. Ghandehari S, Matusov Y, Pepkowitz S, Stein D, Kaderi T, Narayanan D, et al. Progesterone in addition to standard of care vs standard of care alone in the treatment of men hospitalized with moderate to severe COVID-19: a randomized, controlled pilot trial. Chest. 2021;160:74-84.

79. Hashimoto K, Fujita Y, lyo M. Phencyclidine-induced cognitive deficits in mice are improved by subsequent subchronic administration of fluvoxamine: role of sigma-1 receptors. Neuropsychopharmacology. 2007;32:514-21.

80. Li C, Wang A, Wu Y, Gulbins E, Grassmé H, Zhao Z. Acid sphingomyelinaseceramide system in bacterial infections. Cell Physiol Biochem. 2019;52:280-301.

81. Beckmann N, Becker KA. Ceramide and related molecules in viral infections. Int J Mol Sci. 2021;22:5676.

82. Törnquist K, Asghar MY, Srinivasan V, Korhonen L, Lindholm D. Sphingolipids as modulators of SARS-CoV-2 infection. Front Cell Dev Biol. 2021;9:689854.

83. Kornhuber J, Hoertel N, Gulbins E. The acid sphingomyelinase/ceramide system in COVID-19. Mol Psychiatry. 2021. https://doi.org/10.1038/s41380-021-01309-5.

84. Kornhuber J, Tripal P, Reichel M, Mühle C, Rhein C, Muehlbacher $M$, et al. Functional inhibitors of acid sphingomyelinase (FIASMAs): a novel pharmacological group of drugs with broad clinical applications. Cell Physiol Biochem. 2010; 26:9-20.

85. Gulbins E, Palmada M, Reichel M, Lüth A, Böhmer C, Amato D, et al. Acid sphingomyelinase-ceramide system mediates effects of antidepressant drugs. Nat Med. 2013;19:934-8.

86. Gulbins A, Schumacher F, Becker KA, Wilker B, Soddemann M, Boldrin F, et al. Antidepressants act by inducing autophagy controlled by sphingomyelinceramide. Mol Psychiatry. 2018;23:2324-46.

87. Carpinteiro A, Edwards MJ, Hoffmann M, Kochs G, Gripp B, Weigang S, et al. Pharmacological inhibition of acid sphingomyelinase prevents uptake of SARSCoV-2 by epithelial cells. Cell Rep Med. 2020;1:100142.

88. Loas $G$, Le Corre P. Update on functional inhibitors of acid sphingomyelinase (FISMAs) in SARS-CoV-2 infection. Pharm (Basel). 2021;14:691.

89. Kornhuber J, Muehlbacher M, Trapp S, Pechmann S, Friedl A, Reichel M, et al. Identification of novel functional inhibitors of acid sphingomyelinase. PLoS ONE. 2011;6:e23852.

90. Hoertel N, Sánchez-Rico M, Gulbins E, Kornhuber J, Carpinteiro A, Lenze EJ, et al. Association between FIASMAs and reduced risk of intubation or death in individuals hospitalized for severe COVID-19: an observational multicenter study. Clin Pharm Ther. 2021;110:1498-511.

91. Plaze $M$, Attali $D$, Prot $M$, Petit AC, Blatzer $M$, Vinckier $F$, et al. Inhibition of the replication of SARS-CoV-2 in human cells by the FDA-approved drug chlorpromazine. Int J Antimicrob Agents. 2021;57:106274.

92. Hoertel N, Sánchez-Rico M, Cougoule C, Gulbins E, Kornhuber J, Carpinteiro $A$, et al. Repurposing antidepressants inhibiting the sphingomyelinase acid/ceramide system against COVID-19: current evidence and potential mechanisms. Mol Psychiatry. 2021. https://doi.org/10.1038/s41380021-01254-3.

93. Zhang R, Wang X, Ni L, Di X, Ma B, Niu S, et al. COVID-19: Melatonin as a potential adjunct treatment. Life Sci. 2020;250:117583.

94. Anderson G, Reiter RJ. Melatonin: roles in influenza, Covid-19, and other infections. Rev Med Virol. 2020;30:e2109.

95. Anderson GM. Fluvoxamine, melatonin and COVID-19. Psychopharmacology. 2021;238:611.

96. Salata C, Calistri A, Parolin C, Baritussio A, Palù G. Antiviral activity of cationic amphiphilic drugs. Expert Rev Anti Infect Ther. 2017;15:483-92.

97. Glebov OO. Low-dose fluvoxamine modulates endocytic trafficking of SARSCoV-2 spike protein: a potential mechanism for anti-COVID-19 protection by antidepressants. Front Pharmacol. 2021;21:787261.

98. Fred SM, Kuivanen S, Ugurlu H, Casarotto PC, Levanov L, Saksela K, et al. Antidepressant and antipsychotic drugs reduce viral infection by SARS-CoV-2 and fluoxetine show antiviral activity against the novel variants in vitro. bioRxiv 10.110/2021.03.22.436379 [Preprint].

99. Brown AS, Patterson PH. Maternal infection and schizophrenia: implications for prevention. Schizophr Bull. 2011;37:284-90.

100. Patterson PH. Maternal infection and immune involvement in autism. Trends Mol Med. 2011;17:389-94.

101. Brown AS, Meyer U. Maternal immune activation and neuropsychiatric illness: a translational research perspective. Am J Psychiatry. 2018;175:1073-83.

102. Brown AS, Begg MD, Gravenstein S, Schaefer CA, Wyatt RJ, Bresnahan M, et al. Serologic evidence of prenatal influenza in the etiology of schizophrenia. Arch Gen Psychiatry. 2004;61:774-80.

103. Atladóttir HO, Thorsen $P$, Østergaard L, Schendel DE, Lemcke S, Abdallah M, et al. maternal infection requiring hospitalization during pregnancy and autism spectrum disorders. J Autism Dev Disord. 2010;40:1423-30.

104. Islam MM, Poly TN, Walther BA, Yang HC, Wang CW, Hsieh WS, et al. Clinical characteristics and neonatal outcomes of pregnant patients with COVID-19: a systematic review. Front Med. 2020;7:573468.

105. Tanacan A, Yazihan N, Erol SA, Anuk AT, Yetiskin FDY, Burken D, et al. The impact of COVID-19 infection on the cytokine profile of pregnant women: a prospective case-control study. Cytokine. 2021;140:155431.

106. Makvandi S, Mahdavian M, Kazemi-Nia G, Vahedian-Azimi A, Guest PC, Karimi L, et al. The 2019 novel coronavirus disease in pregnancy: a systematic review. Adv Exp Med Biol. 2021;1321:299-307.

107. Ciapponi A, Bardach A, Comandé D, Berrueda M, Argento FJ, Cairoli FR, et al. COVID-19 and pregnancy: an umbrella review of clinical presentation, vertical transmission, and maternal and perinatal outcomes. PLoS ONE. 2021;16: e0253974.

108. Villar J, Ariff S, Gunier RB, Thiruvengadam R, Rauch S, Kholin A, et al. Maternal and neonatal morbidity and mortality among pregnant women with and without COVID-19 infection: the INTERCOVID multinational cohort study. JAMA Pediatr. 2021;175:817-26.

109. Shimabukuro TT, Kim SY, Meyers TR, Moro PL, Oduyebo T, Panagiotakopoulos L, et al. Preliminary findings of mRNA Covid-19 vaccine safety in pregnant persons. N. Eng J Med. 2021;384:2273-82. 
110. Matsuura A, Ishima T, Fujita $Y$, Iwayama $Y$, Hasegawa S, Kawahara-Miki R, et al. Dietary glucoraphanin prevents the onset of psychosis in the adult offspring after maternal immune activation. Sci Rep. 2018;8:2158.

111. Fujita $Y$, Fujita A, Ishima $T$, Hirai A, Suzuki $S$, Suganuma $H$, et al. Dietary intake of glucoraphanin during pregnancy and lactation prevents the behavioral abnormalities in the offspring after maternal immune activation. Neuropsychopharmacol Rep. 2020;40:268-74.

112. Hashimoto K. Recent advances in the early intervention in schizophrenia: future direction from preclinical findings. Curr Psychiatry Rep. 2019;21:75.

113. Hashimoto K. Risk of neuropsychiatric disorders in offspring of COVID-19infected pregnant women and nutritional intervention. Eur Arch Psychiatry Clin Neurosci. 2021;271:387-9.

114. Li Y, Freedman R. Prospects for improving future mental health of children through prenatal maternal micronutrient supplementation in China. Pediatr Investig. 2020;4:118-26.

115. Lins B. Maternal immune activation as a risk factor for psychiatric illness in the context of the SARS-CoV-2 pandemic. Brain Behav Immun Health. 2021; 16:100297.

116. Hoffman MC, Freedman R, Law AJ, Clark AM, Hunter SK. Maternal nutrients and effects of gestational COVID-19 infection on fetal brain development. Clin Nutr ESPEN. 2021;43:1-8.

117. Andalib S, Emamhadi MR, Yousefzadeh-Chabok S, Shakouri SK, Høilund-Carlsen PF, Vafaee MS, et al. Maternal SSRI exposure increases the risk of autistic offspring: a meta-analysis and systematic review. Eur Psychiatry. 2017;45:161-6.

118. Mezzacappa A, Lasica PA, Gianfagna F, Cazas O, Hardy P, Falissard B, et al. Risk for autism spectrum disorders according to period of prenatal antidepressant exposure: a systematic review and meta-analysis. JAMA Pediatr. 2017;171:555-63.

119. Sujan AC, Rickert ME, Öberg AS, Quinn PD, Hernández-Díaz S, Almqvist $C$, et al. Associations of maternal antidepressant use during the first trimester of pregnancy with preterm birth, small for gestational age, autism spectrum disorder, and attention-deficit/hyperactivity disorder in offspring. JAMA. 2017;317:1553-62.

120. Dragioti E, Solmi M, Favaro A, Fusar-Poli P, Dazzan P, Thompson T, et al. Association of antidepressant use with adverse health outcomes: a systematic umbrella review. JAMA Psychiatry. 2019;76:1241-55.

121. Vega ML, Newport GC, Bozhdaraj D, Saltz SB, Nemeroff CB, Newport DJ. Implementation of advanced methods for reproductive pharmacovigilance in autism: a meta-analysis of the effects of prenatal antidepressant exposure. Am J Psychiatry. 2020;177:506-17.

122. Tomfohr-Madsen LM, Racine N, Giesbrecht GF, Lebel C, Madigan S. Depression and anxiety in pregnancy during COVID-19: A rapid review and meta-analysis. Psychiatry Res. 2021;300:113912.
123. Kreuzberger N, Hirsch C, Chai KL, Tomlinson E, Khosravi Z, Popp M, et al. SARSCoV-2-neutralising monoclonal antibodies for treatment of COVID-19. Cochrane Database Syst Rev. 2021;9:CD013825

124. Mahase E. Covid-19: molnupiravir reduces risk of hospital admission or death by $50 \%$ in patients at risk, MSD reports. BMJ. 2021;375:n2422.

125. Sidik SM. Common antidepressant slashes risk of COVID-19 death. Nature. 2021 https://doi.org/10.1038/d41586-021-02988-4.

\section{ACKNOWLEDGEMENTS}

The authors would like to thank our collaborators who are listed as the coauthors of our papers in the reference list. We also thank to Dr. Yan Wei for preparation of Fig. 2.

\section{AUTHOR CONTRIBUTIONS}

Y.H., T.S., and K.H. did the reference search and wrote the manuscript. Y.H. and K.H. prepared the figures and table. All authors approved the final manuscript.

\section{CONFLICT OF INTEREST}

Dr. Y. Hashimoto and Dr. T. Suzuki have no conflict of interest. Dr. K. Hashimoto is the inventor of filed patent applications on "The use of $R$-Ketamine in the treatment of psychiatric diseases", "(S)-norketamine and salt thereof as pharmaceutical", " $R$ Ketamine and derivative thereof as a prophylactic or therapeutic agent for neurodegeneration disease or recognition function disorder", "Preventive or therapeutic agent and pharmaceutical composition for inflammatory diseases or bone diseases", and "R-Ketamine and its derivatives as a preventive or therapeutic agent for a neurodevelopmental disorder" by the Chiba University. Dr. K. Hashimoto has also received speakers' honoraria, consultant fees, or research support from Abbott, Meiji Seika Pharma, Dainippon-Sumitomo, Taisho, Otsuka, Murakami Farm, and Perception Neuroscience.

\section{ADDITIONAL INFORMATION}

Correspondence and requests for materials should be addressed to Kenji Hashimoto.

Reprints and permission information is available at http://www.nature.com/reprints

Publisher's note Springer Nature remains neutral with regard to jurisdictional claims in published maps and institutional affiliations. 